\title{
Divergent axial morphogenesis and early shh expression in vertebrate prospective floor plate
}

\author{
Stanislav Kremnyov ${ }^{1,2}$ (D) Kristine Henningfeld ${ }^{3}$, Christoph Viebahn ${ }^{4}$ and Nikoloz Tsikolia ${ }^{4^{*}}$ (D)
}

\begin{abstract}
Background: The notochord has organizer properties and is required for floor plate induction and dorsoventral patterning of the neural tube. This activity has been attributed to sonic hedgehog (shh) signaling, which originates in the notochord, forms a gradient, and autoinduces shh expression in the floor plate. However, reported data are inconsistent and the spatiotemporal development of the relevant shh expression domains has not been studied in detail. We therefore studied the expression dynamics of shh in rabbit, chicken and Xenopus laevis embryos (as well as indian hedgehog and desert hedgehog as possible alternative functional candidates in the chicken).

Results: Our analysis reveals a markedly divergent pattern within these vertebrates: whereas in the rabbit shh is first expressed in the notochord and its floor plate domain is then induced during subsequent somitogenesis stages, in the chick embryo shh is expressed in the prospective neuroectoderm prior to the notochord formation and, interestingly, prior to mesoderm immigration. Neither indian hedgehog nor desert hedgehog are expressed in these midline structures although mRNA of both genes was detected in other structures of the early chick embryo. In X. laevis, shh is expressed at the beginning of gastrulation in a distinct area dorsal to the dorsal blastopore lip and adjacent to the prospective neuroectoderm, whereas the floor plate expresses shh at the end of gastrulation.

Conclusions: While shh expression patterns in rabbit and $X$. laevis embryos are roughly compatible with the classical view of "ventral to dorsal induction" of the floor plate, the early shh expression in the chick floor plate challenges this model. Intriguingly, this alternative sequence of domain induction is related to the asymmetrical morphogenesis of the primitive node and other axial organs in the chick. Our results indicate that the floor plate in X. laevis and chick embryos may be initially induced by planar interaction within the ectoderm or epiblast. Furthermore, we propose that the mode of the floor plate induction adapts to the variant topography of interacting tissues during gastrulation and notochord formation and thereby reveals evolutionary plasticity of early embryonic induction.
\end{abstract}

Keywords: Evo-devo, Gastrulation, Induction, Neural tube, Notochord, Sonic hedgehog, Vertebrates

\section{Background}

The brain and spinal cord display characteristic functional and structural differences along the dorsoventral axis. Differences are derived from unique combinatorial gene expression in the progenitor domains of the neural tube, which leads to development of distinct types of

\footnotetext{
*Correspondence: nikoloz.tsikolia@med.uni-goettingen.de

${ }^{4}$ Institute of Anatomy and Embryology, University Medical Center

Göttingen, Kreuzbergring 36, 37085 Göttingen, Germany

Full list of author information is available at the end of the article
}

neurons [26]. The unique gene expression in the progenitor domains is suggested to be the result of fine-tuned signaling activities related to gradients of secreted morphogens [13]. Sonic hedgehog (shh) forms a ventral-todorsal gradient and is expressed in the floor plate and the notochord. The shh gradient in turn induces a gradient of GliA and GliB transcriptional factor activity, which together with Sox2 participates in the formation of distinct gene expression domains [53]. Similarly, Wnt and Bmp signaling is active from the dorsal pole of the neural tube and from the superficial ectoderm [12, 40, 44]. 
The initial dorsoventral patterning of the neural tube exemplifies a classical induction from neighboring tissue. As inductive interactions belong to central concepts in developmental biology [76], the early role of the notochord serves as a paradigmatic example of induction by organizers, which are defined by their ability to induce and pattern adjacent tissue [3]. Early studies in amphibian embryos suggested that the notochord is required for correct morphological dorsoventral patterning of the neural tube [37], while other observations indicated, however, that a more cautious interpretation is needed $[38,75]$. Similarly, the notochord in the chick was shown to be required for floor plate development as well for its specific inductive function [59, 90]. For example, implantation of the notochord lateral to the neural tube causes ventralization of the lateral tube wall and formation of ectopic floor plate, as seen by cell shape change or ectopic axon outgrowth [59, 91].

Shh has been shown to be strongly expressed both in the notochord and in the floor plate of different organisms and to have the ability to induce a floor plate when expressed ectopically [18, 31, 65]. Importantly, an isolated shh-expressing floor plate forms a gradient of shh within the neural tube and is also able to induce a ventral fate in the adjacent neural tissue [60], which indicates that the floor plate also has organizer activity [3]. Therefore, the role of the notochord may be related to expression and secretion of shh, which induces its own expression in prospective floor plate cells. According to this hypothesis, shh expression in the notochord must precede its expression in the floor plate and, indeed, this has been unambiguously shown in mouse $[10,18]$ and rat [65] embryos. It has been suggested that the six progenitor domains responsible for dorsoventral differences in the ventral neural tube are induced even prior to shh expression in the floor plate [64] and, therefore, if the shh gradient is causally involved in this induction, the notochord must be the primary source of the gradient.

However, the universality of the notochord's organizer role is under debate $[36,50]$. In zebrafish, for example, neither mechanical ablation of the notochord progenitors [71] nor disturbed notochord development in no tail (ntl) mutants [28] inhibits floor plate development. Moreover, it was shown that hedgehog signaling is not required for development of the medial floor plate, but is involved in development of so-called lateral floor plate $[48,67]$. Similarly, in Xenopus laevis, shh signaling has a minor influence on medial floor plate markers, while a strong suppression of the lateral floor plate marker $n k x 2.2$ occurs upon inhibition of shh signaling [54]. Although chicken embryos remain a classical model organism for floor plate induction [14, 63], the situation here is still complex: Replacement of the chicken node at 5-6 somite stages by their quail counterpart shows that both the floor plate and the notochord caudal to the explant develop from the node, while in situ analysis has shown that both structures express continuously HNF3 beta [85]. Based on shared progeny and gene expression as well as on results from experiments with notochord excision in 10-25 somite stages [85], Nicole Le Douarine and colleagues suggested that the notochord is not required for the chick floor plate induction [36, 85]. However, this conclusion was criticized $[58,63]$. It was argued that the shared progeny and HNF3 beta expression is not relevant since node cells which become floor plate immediately lose shh expression within the neural environment and the expression domain is then de novo induced by shh protein secreted from the notochord [58]. James Briscoe and colleagues also argue in favor of the model assuming floor plate specification by shh from the notochord in amniotes [63]: inhibition of hedgehog signaling in both mouse and chick embryos impairs the floor plate identity only if the downregulation of hedgehog signaling occurs prior to 5-10 somite stages. Hence, floor plate induction by the notochord may occur earlier as previously believed and the results provided by the group of Nicole Le Douarine concern stages with already induced floor plate and cannot challenge the role of the notochord in the floor plate induction [63]. Further investigations [50] led to a modified model which postulates that a prolonged signal from the notochord is required for the posterior floor plate regions, which includes hindbrain and spinal cord and starts to form at stage 5, whereas the induction of anterior floor plate regions is caused by migrating prechordal plate mesoderm. Partial ablation of the chick notochord shortly after the beginning of its formation (HH stage $5-$ ) does not suppress differentiation of anterior (mid- and forebrain) floor plate as seen by shh expression. This model suggests also involvement of nodal signaling in anterior floor plate induction [50].

Remarkably, in spite of the controversy about the source of the signal leading to floor plate induction, the early expression domains of shh in the chick embryo have not been studied in detail to date in the tissues and stages involved. As shown in a different context, shh is expressed prior to the notochord formation in the area of the primitive node already at stage $4[17,39]$. At this stage, shh displays a dense symmetrical domain in both node ectoderm and mesoderm of the primitive pit, in the neuroectoderm just anterior to the node as well as a scattered expression in the emerging mesoderm anterior to the node [86]. Furthermore, our previous studies suggested a left-right asymmetry of the chick axial organ formation. Whereas the notochord forms from the right node shoulder, the floor plate exhibits tissue continuity with the left side of the primitive node [49] 
and analysis of histological sections revealed an unexpected localization of shh expression in the early floor plate. Therefore, we studied in detail the succession of shh expression in the node, prechordal mesoderm, notochord and floor plate of the chick embryo. As shh expression in the chick differs from spatiotemporal dynamics of shh expression in mammals as exemplified by the early mouse embryonic cylinder, the need arose to clarify a possible evolutionary divergence of floor plate induction and we therefore analyzed shh expression at comparable stages in rabbit embryos (displaying a flat embryonic disk - in contrast to the mouse-typical for most mammals $[78,92]$ ), as well in (anamniote) X. laevis embryos. As the expression of hedgehog family members Indian hedgehog and desert hedgehog displays highly divergent patterns at early stages in zebrafish, Xenopus, mouse and rabbit $[8,19,20,97]$, we also studied their expression in the chick. The results of this study challenge the model of "the ventral to dorsal induction" of shh expression [89] in the midline and indicate an evolutionary divergence of floor plate induction, which may explain the contradictory data mentioned above. Interestingly, early floor plate induction in the chick embryo is in line with data showing that neural induction in the chick starts even prior to gastrulation by precursor cells of the organizer [81]. Our comparative analysis of spatiotemporal succession of shh expression at perigastrulation stages may have an impact on evolutionary scenarios of dorsoventral patterning and pave the way for further functional studies on the notochord's organizer function. Last but not least, our analysis is important because the "notochord first" view of shh expression is taken for granted in most recent publications and is widely presented in textbooks of developmental biology.

\section{Materials and methods}

Fertilized white leghorn chicken eggs were incubated under humidified conditions at $38{ }^{\circ} \mathrm{C}$ for $6-40 \mathrm{~h}$ until embryos reached stages between 2 and 9 (see [86]). To collect chick embryos, the eggshell was opened and the embryos were prefixed in fixative. After excision of blastoderm, embryos were transferred into a Petri dish with warm Locke's solution, rinsed to remove adherent yolk particles and fixed in 4\% PFA in phosphate-buffered saline (PBS) for $1 \mathrm{~h}$. Uterine horns of New Zealand white rabbits were removed and transferred into warm $\left(37{ }^{\circ} \mathrm{C}\right)$ phosphate-buffered saline (PBS). Blastocysts were excised from endometrium, and the blastodisk was isolated and fixed in 4\% PFA for $1 \mathrm{~h}$ (see [69]). Fixed chicken and rabbit embryos were washed several times in PBS, dehydrated by ascending alcohol concentrations and stored in ethanol at $-20{ }^{\circ} \mathrm{C}$. For in situ hybridization of chicken and rabbit embryos, selected embryos were transferred to nylon baskets, rehydrated, treated with $10 \mathrm{mg} / \mathrm{ml}$ proteinase K (Roche, Grenzach-Wyhlen, Germany) in PBT for $10 \mathrm{~min}$ and postfixed in $0.2 \%$ glutaraldehyde/PBT for $20 \mathrm{~min}$. For the prehybridization and hybridization, the baskets with embryonic disk were transferred to sterile screw-top PVC tubes (Bibby Sterilin, Staffordshire, UK). After $1 \mathrm{~h}$ prehybridization at $70{ }^{\circ} \mathrm{C}$ in a heating block in hybridization buffer $[50 \%$ formamide, 1.4X SSC, $0.1 \% 0.5 \mathrm{mM}$ EDTA, $50 \mu \mathrm{g} / \mathrm{ml}$ t-RNA, 0.2\% Tween-20, 0.5\% CHAPS, $50 \mu \mathrm{g} / \mathrm{ml}$ heparin (AppliChem, Darmstadt, Germany)], the embryos were hybridized overnight at $70{ }^{\circ} \mathrm{C}$ in hybridization buffer with $1 \mu \mathrm{g} / \mathrm{ml}$ digoxygenin-labeled cRNA denatured at $95{ }^{\circ} \mathrm{C}$. Labeled cRNA of chicken and rabbit shh and patched 2 was synthesized by in vitro transcription from PCR products of previously published plasmid DNA [2, $25,39,51]$ or from PCR product of a synthetically produced probe corresponding to bp 911-1714 of chicken dhh (GenBank accession number: XM_015300320.1) and 729-1405 bp of chicken ihh (GenBank accession number: NM_204957.2) was obtained from BioCat (Heidelberg, Germany). In the next step, embryos were washed in prewarmed hybridization buffer and MABT (100 mM maleic acid, $150 \mathrm{mM} \mathrm{NaCl}, 0.1 \%$ Tween20, $\mathrm{pH}$ 7.5). Subsequently, baskets with embryos were transferred in MABT with 2\% Roche blocking reagent and $20 \%$ heat-inactivated goat serum. Hybridized RNA was visualized with antidigoxigenin antibody coupled to alkaline phosphatase and BM purple substrate (both Roche, Mannheim, Germany). To initiate the color reaction, embryos were transferred to Petri dishes filled with the substrate and the reaction was allowed to proceed at room temperature in the dark for 2-5 days. Xenopus leavis embryos were obtained by hormone-induced egg laying and in vitro fertilization using standard methods [73]. Embryos were fixed in MEMFA and staged according to Nieuwkoop and Faber [46]. Whole-mount in situ hybridization was performed using digoxygenin-labeled antisense probes [73]. Xenopus shh construct was previously described (Ekker et al. [19, 20], and patched 2 construct was produced by PCR product from Xenopus cDNA corresponding to bp 2045-2751 (GenBank accession number: NM_001136166.1) using primer combination: XlPtch2L dir; ATTTCCACGTCACCCTCAGTCATT (forward) and GGTATCAGCCCCTTCTCATCCAC (reverse).

All embryos were photographed as whole mounts in Mowiol (Carl Roth, Karlsruhe, Germany) and embedded in Technovit $8100 \mathrm{~s}$ (Heraeus Kulzer, Wehrheim, Germany). Serial 5-10-mm sections were cut at sectional planes predefined in whole-mount views and photographed using bright-field illumination or Nomarski contrast. 


\section{Results}

Axial expression of hedgehog genes in the chick

In $\mathrm{HH}$ stage 5 [29] chicken embryos, which are at the beginning of notochord formation and concomitant primitive streak regression, a shh-positive area appears as a stripe-like expression in the midline anterior to the node (Fig. 1a and Additional file 1: Fig. 1A), whereas the node domain displays progressive left-right asymmetry [86]. Importantly, analysis of technovit sections reveals that, at stages 5 (Fig. $1 \mathrm{~d}$ and Additional file 1: Fig. 1D) and 6 (Fig. 1e), this shh-positive area lies posteriorly above a shh-negative or shh-weakly positive notochord. In the middle of the neural plate, both the midline mesoderm and the neuroectoderm are shh positive (Fig. 1D and Additional file 1: Fig. 1C), whereas in the area corresponding to the anterior neuroectoderm and the prechordal plate, the (upper) ectodermal layer is negative (Fig. 1D and Additional file 1: Fig. 1B). At $\mathrm{HH}$ stage 6 (Fig. 1b, e), expression extends in the posterior direction in both layers. Interestingly, at the level of the forebrain rudiment and head fold, the anterior expression is confined to epithelialized cells within the endoderm, whereas at stage 5 the expression in this area is confined to mesenchymal cells of prechordal mesoderm. Positive columnar cells within the endoderm display a columnar morphology and correspond to the preoral gut. In addition, at stage 6 , scattered shh-positive mesenchymal cells are positioned at the anterior edge of the neural plate, thus forming a continuous border around the entire area pellucida (Fig. 1b). Analysis of shh expression at stage 8 (Fig. 1c, f-i) reveals expression along the whole notochord, in the prechordal mesoderm and in the anterior border of endoderm corresponding to so-called preoral gut and therefore to cells of the future Seessel's pouch. The expression in the midline neuroectoderm remains strong and includes posterior regions, whereas expression in the forebrain area is not yet induced. In the node, shh domain is confined to the epiblast, while the adjacent

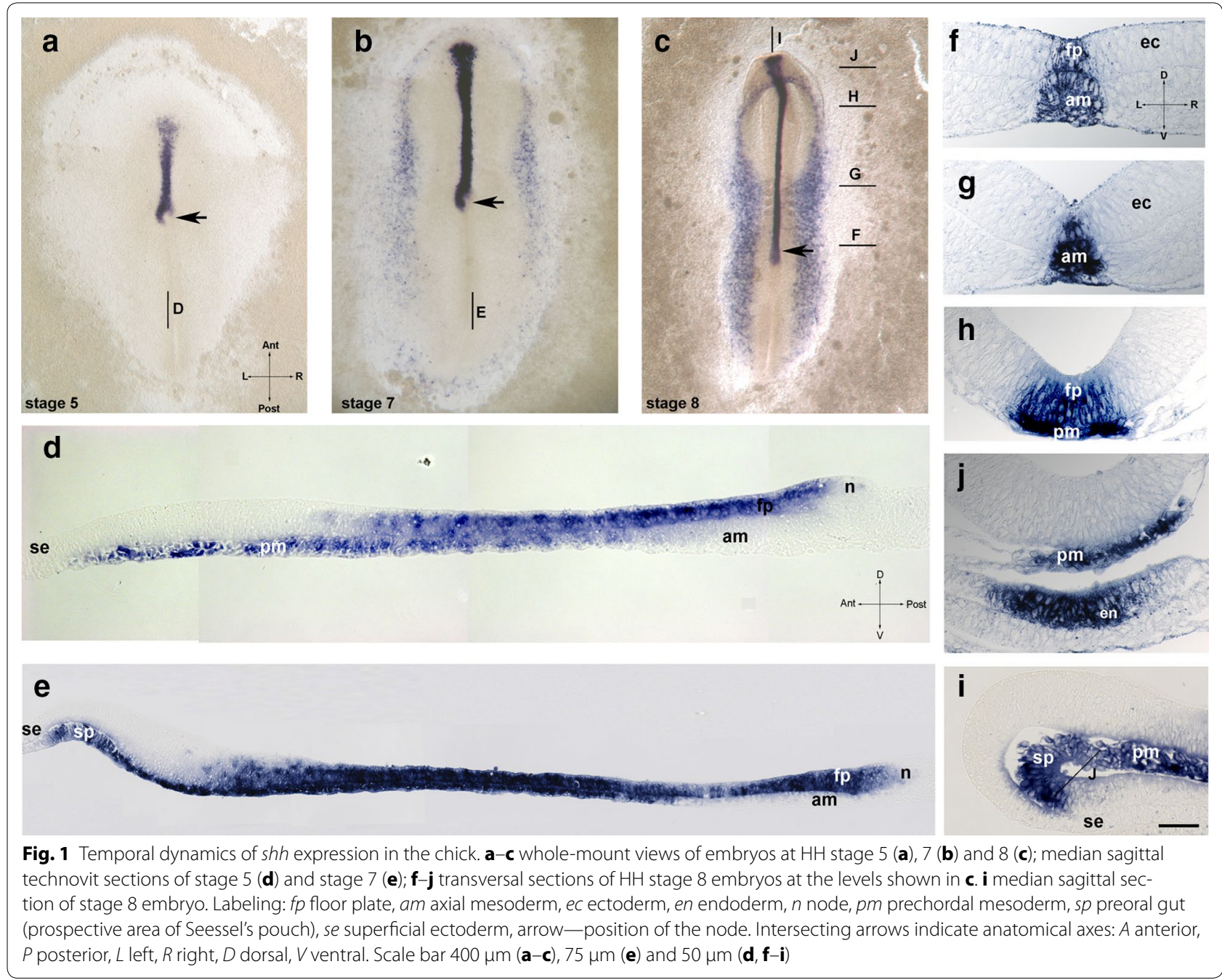


notochord displays weak positivity. Summarizing shh is expressed in the prospective floor plate (except for its anterior part) in all serially sectioned chicken specimens $(N=37)$.

Since $s h h$ is expressed in the prospective floor plate from the beginning of the notochord formation as well as in the node, we asked whether its expression is initiated prior to node and prechordal mesoderm formation. Surprisingly, chick embryos are shh positive already between stages 2 and 3 (Fig. 2a). At this stage, the primitive streak appears as a density extending from the posterior pole to the center of the blastodisk and is in its posterior part wider and resembles an isosceles triangle [29]. The expression of shh is strong and related to the zone in the front of the medial thickening and in its anterior area. The area anterior to the primitive streak density has been shown to correspond to the prospective neuroectoderm, especially to the future floor plate, whereas the anterior portion of the primitive streak gives rise to the prechordal mesoderm and notochord [42, 79]. Transverse technovit sections near the posterior border of staining reveal a medial thickening with a groove (Fig. 2c), which corresponds to the anterior part of the primitive streak. Sections at the anterior level (Fig. 2b) reveal expression of heterogeneous intensity, which is confined to epiblast cells displaying a columnar epithelial shape. Additionally, single scattered mesenchyme-like positive cells representing early mesoderm are found under the epiblast. These cells correspond to local EMT areas, which were shown to occur at low intensity at this stage within the entire epiblast [94].
As patched 2, a marker of hedgehog signaling is confined to the midline neuroectoderm including forebrain after the beginning of the node regression $[49,51]$, we analyzed its expression prior to the node regression. Patched 2 expression starts within the area pellucida in a uniform manner at stage 3 (not shown) and from stage 4 onwards is strongly expressed in the anterior epiblast (Additional file 2: Fig. 2). This expression corresponds to the ventral portion of the prospective neural plate and indicates active hedgehog signaling in the upper layer prior to the notochord formation.

Analysis of Indian hedgehog (ihh) and desert hedgehog (dhh) revealed no specific expression in the node, notochord or floor plate between $\mathrm{HH}$ stages 4 and 17 . At stages HH4-HH5 ihh was weakly expressed in the anterior and lateral areas of zona pellucida (Fig. 3a) and at $\mathrm{HH} 6$ and 7 lateral and anterior to the neural plate (Fig. 3b). Sections revealed strong expression in the endodermal layer which persisted at least until stage 17 (Fig. 3c, d). Dhh expression is first seen at stage 11 and is confined to two parallel narrow stripes lateral to paraxial somitic region (Fig. 3e). Sections confirmed expression in the dorsal domain of intermediate mesoderm (Fig. 3f). This expression is maintained and is also seen at stage 17 where $d h h$ is expressed in the mesonephric tubules (Fig. 3g).

Summarizing, the presented data reveal that shh expression domain in the prospective chick neuroectoderm is initiated at early gastrula stage, displays continuity with the left-sided expression in the node epiblast and persists during early somitogenesis.

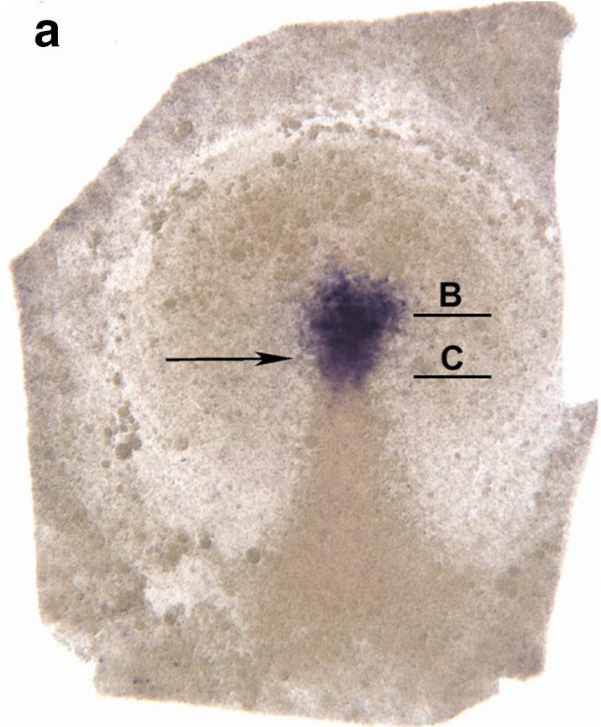

b

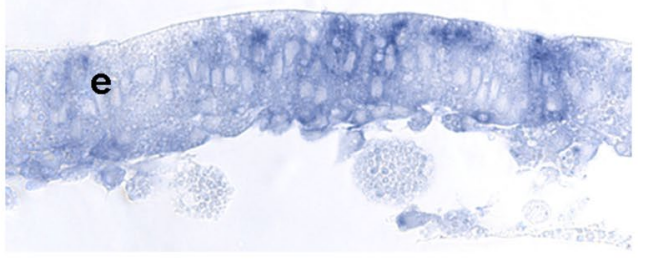

C

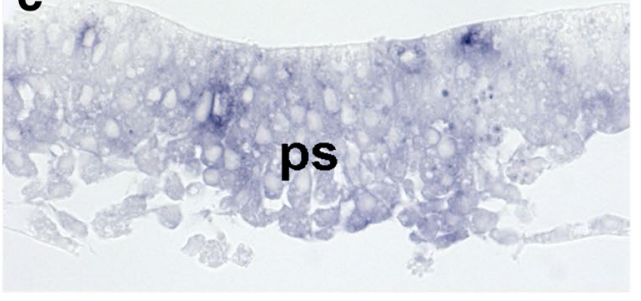

Fig. 2 Early shh expression in the chick stage $2+/ 3-$ embryo. Arrow: position of the tip of the primitive streak 


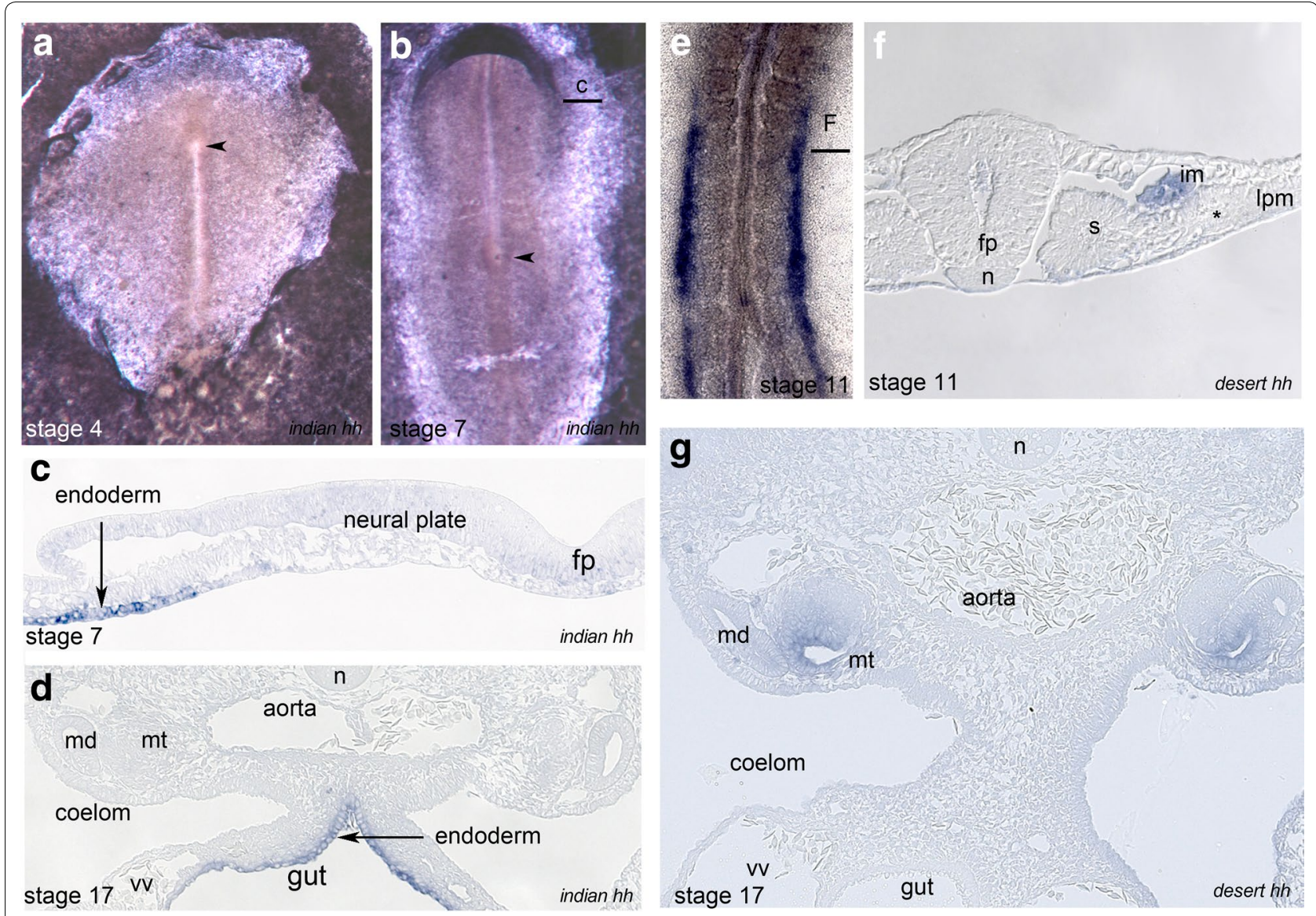

Fig. 3 Expression of Indian hedgehog (ihh) and desert hedgehog (dhh) in the chick. a, b whole-mount views of ihh expression at HH stage 4 (a) and 7 (b). c transversal technovit section of embryo shown in $\mathbf{b}$; $\mathbf{d}$ ihh expression in the gut endoderm (HH stage 17); whole-mount view (e) and section (f) of dhh expression in the dorsal part of intermediate mesoderm (HH stage 11); $\mathbf{f}$ dhh expression in the mesonephric tubules (HH stage 17). $\mathrm{N}$ notochord, fp floor plate, im intermediate mesoderm, s somite, $v V$ vitelline vein, $m d$ mesonephric duct, $m t$ mesonephric tubule, arrowhead-position of the node

\section{Axial shh expression in the rabbit}

Rabbit embryos display a symmetrical shh midline expression domain in the area of emerging notochord (Fig. 4a, b). Analysis of early stage 5 technovit sections anterior to the node shows strong expression in the emerging axial mesoderm (Fig. 4d) and no expression in the dorsal (neuroectodermal) layer, whereas within the node, shh is present in both layers (Fig. 4g). Similarly, at advanced stage 5 (Fig. 3e), the axial mesoderm reveals strong shh expression, while in the midline neuroectoderm, the expression is very weak with the exception of an area located immediately anterior to the node (Fig. 4h). Interestingly, the mesodermal expression is confined to the lateral area of the axial mesoderm, which has been shown to express nodal [69]. Remarkably, the notochord at the level anterior to the node may display an internal cavity indicating appearance of the notochordal canal in the rabbit in some specimens. Similar expression of shh is seen at stage 6 (not shown) and at stage 8 (Fig. 4c, f, j). At later stages, shh-positive cells are seen in the floor plate, notochord and in the dorsal endoderm. The data indicate that shh expression in the rabbit floor plate follows its expression in the notochord, similar to shh expression in the mouse [10].

\section{Axial shh expression in Xenopus laevis}

In $X$. laevis, shh expression starts at early gastrula stage with a sickle-shaped domain in the area above the dorsal blastopore (Fig. 5a). During gastrulation, this domain undergoes narrowing and elongation along the AP axis (Fig. 5b, c). Technovit sections reveal an early gastrula expression domain in the deep layer of the dorsal marginal zone, with expression absent from the dorsal lip and superficial mesoderm (Fig. 6a). The early shh domain corresponds to the area that is known to give rise to the axial mesoderm and is adjacent to the prospective neuroectoderm. At mid-gastrula, expression is confined to the deep involuted layer (Fig. 6b), and at the end of gastrulation, 


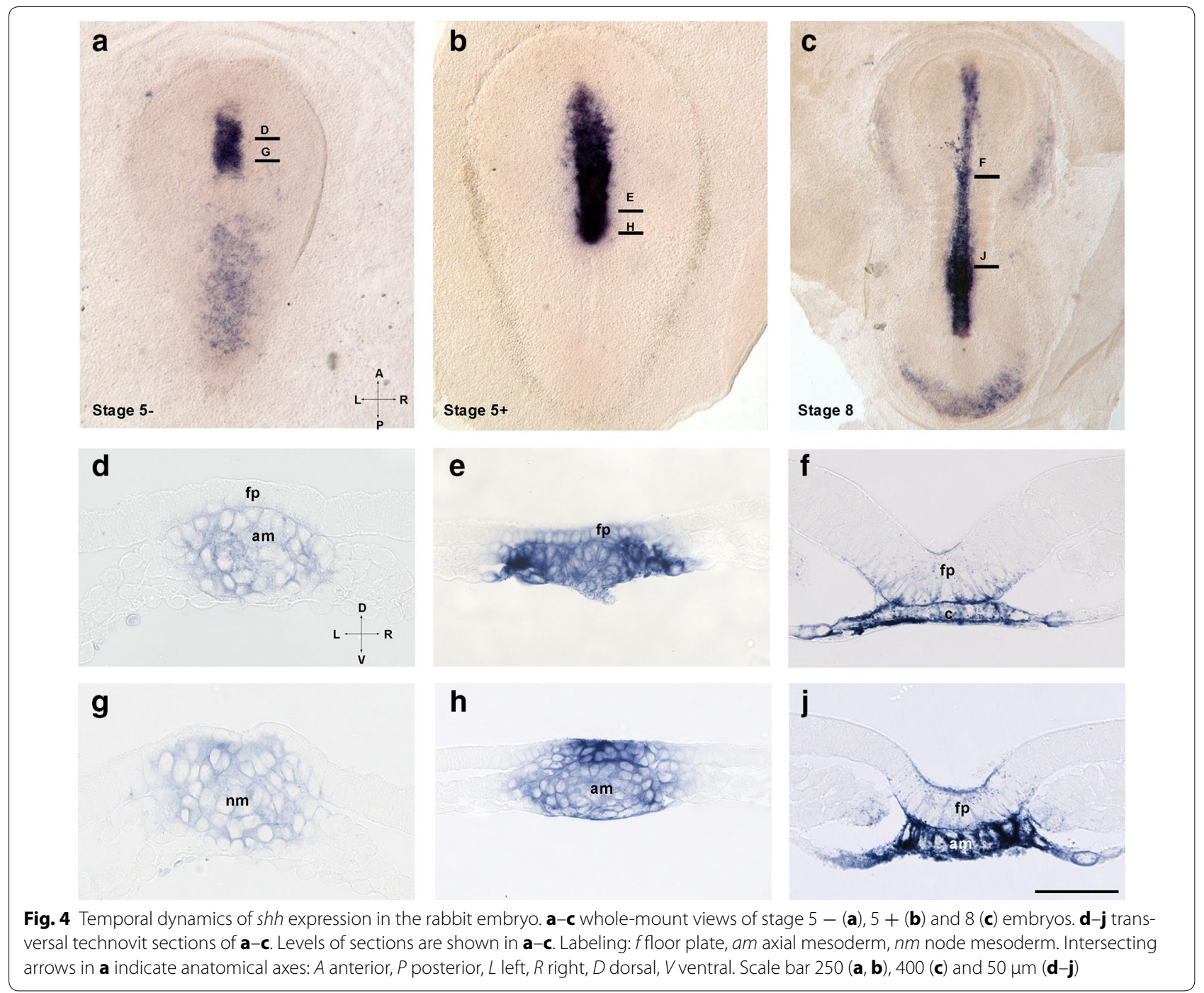

shh expression extends along the dorsal midline (Fig. 5d). Surprisingly, the sections reveal expression in the inner layer of the midline ectoderm and in the midline mesoderm (Fig. 6b, c). The width of the expression in both domains follows differences seen already in whole-mount views with a narrow posterior and wide anterior domain. During neurulation, shh expression undergoes further elongation and narrowing (Fig. 5e). Sections at stage 14 reveal expression in the inner neuroectoderm layer and weak expression in the rod-like notochord. In the anterior neuroectoderm, strong and wide expression is present in both inner cells, which display columnar morphology and in flat outer ectoderm cells. Midline mesoderm, which at this level forms a plate, also displays a strong scattered expression in epithelial-like cells. At the more anterior level (prospective superficial), expression of $s h h$ is present in the mesoderm, but excluded from the overlying ectoderm. At early tailbud stage (Figs. 5f, 6h), shh expression is confined to the floor plate, notochord, hypochord and at the level of the posterior notochord to the archenteron roof. In addition, we found that patched 2 expression is specifically activated in the midline at mid-gastrula stages, suggesting activated hedgehog signaling already at this stage (Fig. 5g). Summarizing, neuroectodermal expression of shh is initiated at late gastrula/ early neurula stages, whereas the mesodermal expression is initiated at early gastrula in the dorsal organizer area.

\section{Discussion}

Shh induction in the chick floor plate does not require a shh signal from the notochord

The first critical conclusion is deduced from the observation that after the beginning of the node regression (HH stage 5 -) shh is expressed in emerging prospective 

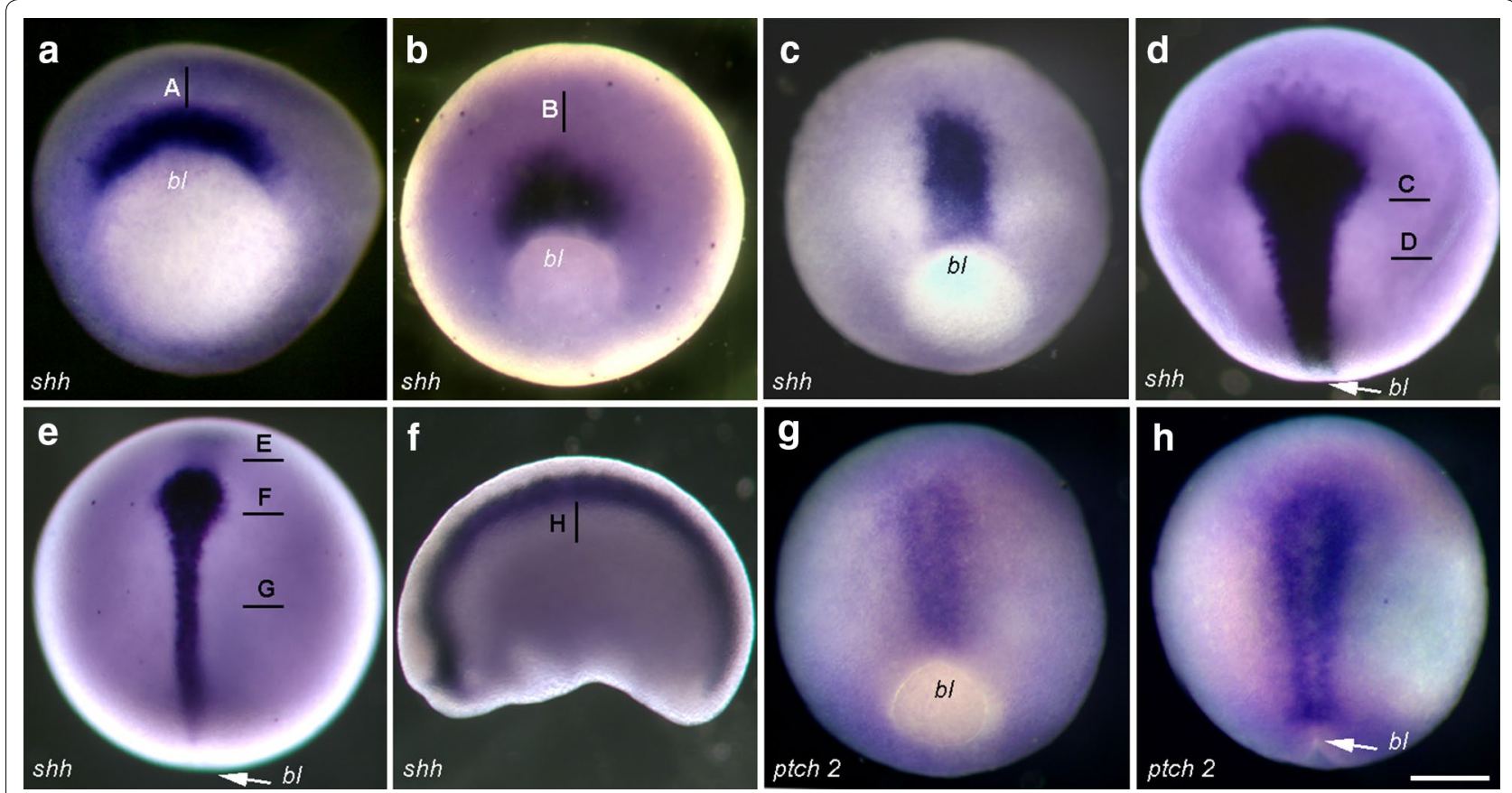

Fig. 5 a-f temporal dynamics of shh expression in Xenopus laevis embryos between early gastrula and tadpole stages. $\mathbf{g}$-h expression of patched 2 at middle (g) and late (h) gastrula stage. b/ Blastopore. Scale bar $200 \mu \mathrm{m}$

floor plate above shh-negative freshly laid down notochord. Moreover, a asymmetrical shh domain in the node remains continuous with the midline floor plate domain. At the same time, the notochord is continuous with a shhnegative right node shoulder [49]. This strongly suggests that during the investigated stages shh in the floor plate domain cannot be induced by shh protein secreted from the notochord. During further development, the elongating shh floor plate domain remains strongly positive at all studied stages, whereas the (ongoing emerging) notochord adjacent to the node remains shh negative until stage 8 . These findings contradict the assumption that during the investigated stages, shh-expressing cells in the node lose shh expression when integrating into the floor plate and reacquire it after induction by shh from the notochord even though this assumption may apply for later stages. Delayed induction of shh in the posterior notochord may be promoted by HNF3 beta which is required for shh expression in mouse [4] and in contrast to shh is expressed in the freshly laid down notochord (see [66] and unpublished). Involvement of Indian and desert hedgehog in early inductive interaction is unlikely as they shown no midline expression.

Further conclusion concerns the "premature" initiation of shh expression at the late stage 2 in the epiblast in the front of the primitive streak as well as in prospective midline mesoderm in the anterior-most primitive streak. According to fate mapping data, the floor plate domain develops from epiblast adjacent and anterior to the node $[22,42,62,79]$. Importantly, an area located at the early stage 3 at the anterior border of the prospective node corresponds to the shh domain that undergoes elongation during node regression and gives rise to floor plate cells within the neural tube with the exception of the forebrain, which emerges from more anterior region [42]. This indicates that the floor plate precursor cells are shh positive prior to mesoderm migration and suggests that floor plate induction may occur already at the beginning of gastrulation, similar to neural induction [81]. Strong expression of patched 2 in the prospective neuroectoderm at stages 4 and $4+$ further supports the "early" activated hedgehog signaling in the prospective floor plate.

Interestingly, fate mapping indicates a specific transformation of the floor plate domain in that the floor plate is recruited from a horseshoe-like domain anterior and lateral to the HH stage $4 / 4$ + node (referred to as "full length primitive streak stage", [23]). This distribution correlates remarkably well with the $s h$ expression pattern: our previous analysis of shh expression between stages $4-$ and $4+$ revealed that the expression domain is first confined to the node, prenodal epiblast and pit mesoderm and thereafter to the scattered mesoderm cells anterior to the node, thus suggesting that at least a part of prechordal plate progenitor cells express shh continuously [86]. The mesodermal expression in the pit ceases at stage $4+$ when the prechordal mesoderm has emerged from the node. 

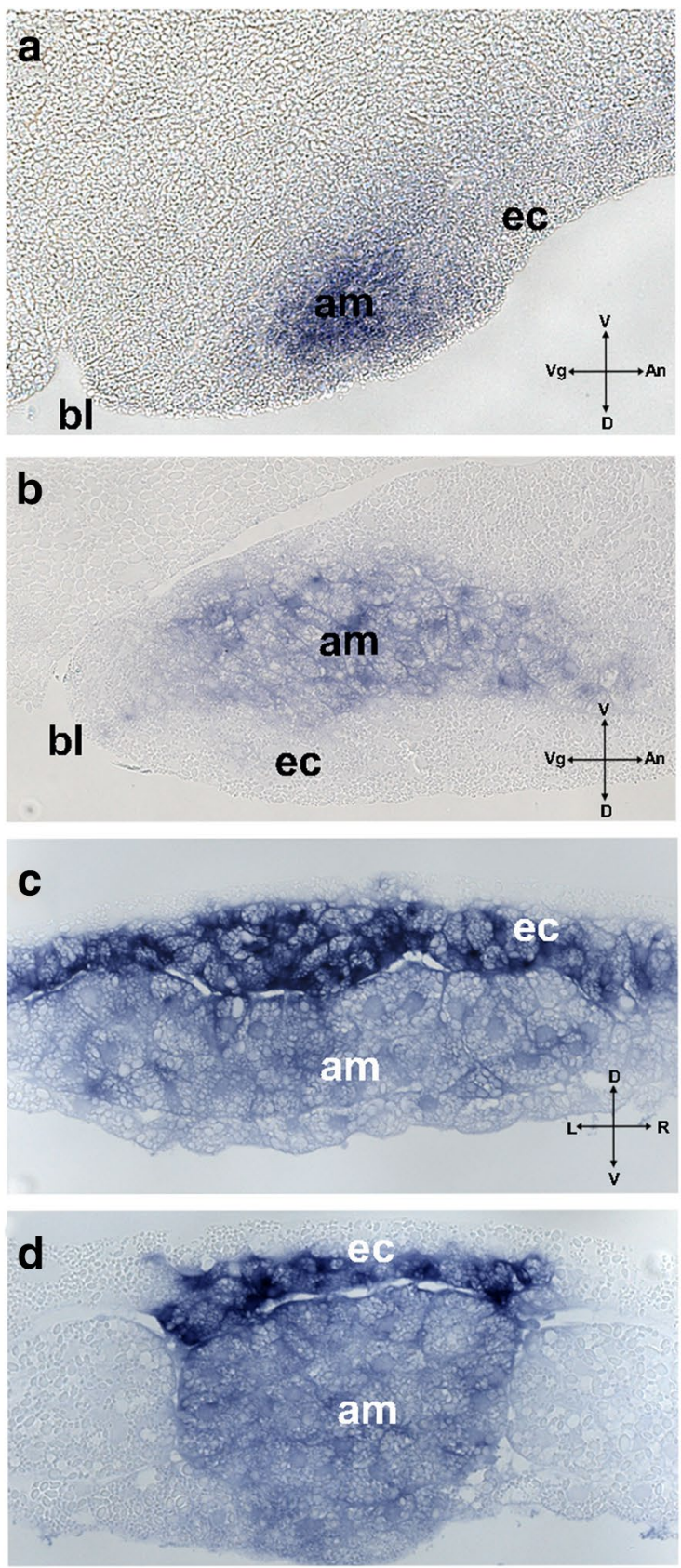
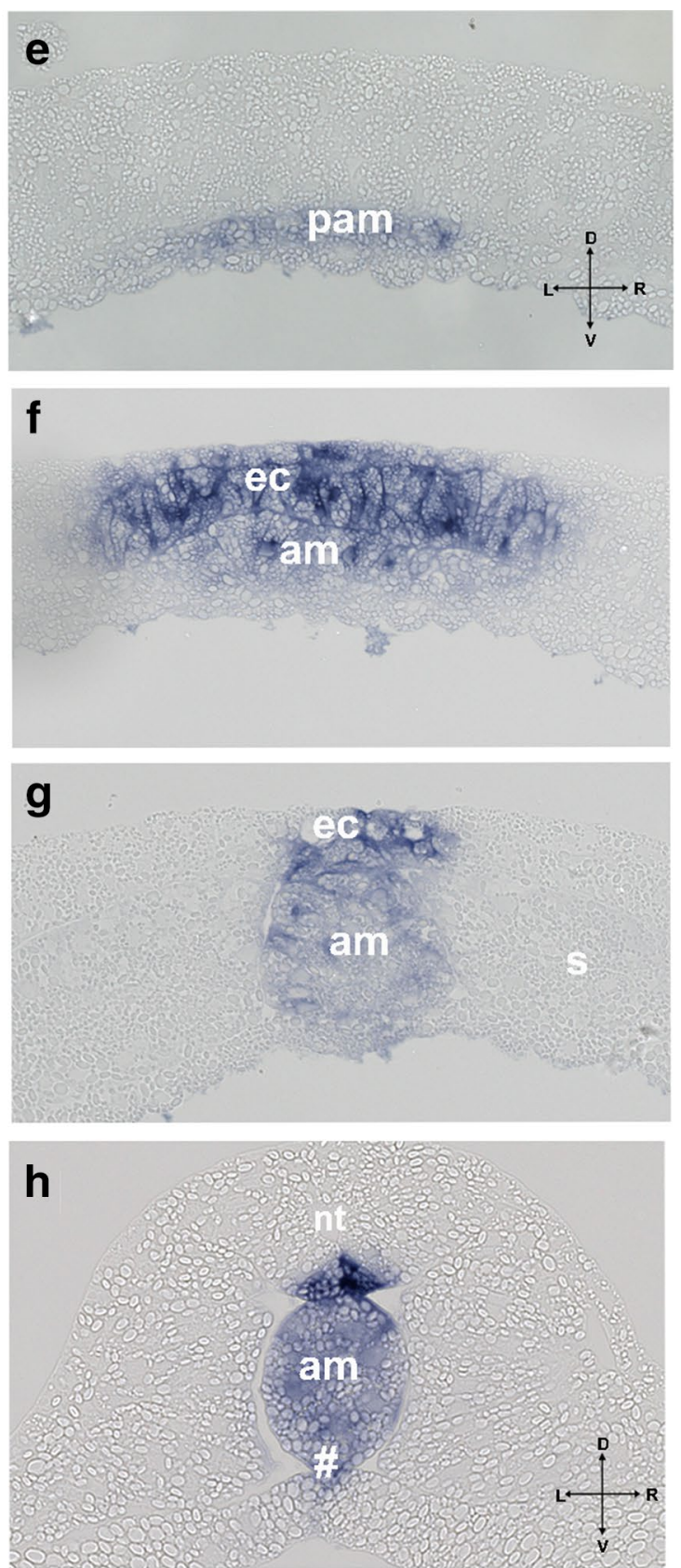

Fig. 6 Technovit sections of Xenopus laevis embryos at early gastrula (a), mid-gastrula (b), late gastrula ( $\mathbf{c}$, $\mathbf{d})$, early neurula $(\mathbf{e}-\mathbf{g})$ and tailbud stage (h) at levels shown in Fig. 3. Labeling: ec midline neuroectoderm, am axial mesoderm, se superficial ectoderm, pam preaxial mesoderm (leading edge), s somites, nt neural tube. Intersecting arrows in indicate anatomical axes: $A$ animal, Veg vegetal, $L$ left, $R$ right, $D$ dorsal, $V$ ventral

Our results require a modification of the so-called dual model for floor plate induction in the chick [50]. According to this model, the anterior floor plate including forebrain and midbrain does not require the notochord and is induced by rapid interaction of shh-negative precursor epiblast (also called area A) with migrating prechordal plate mesoderm, whereas prolonged influence of the notochord is required for floor plate induction in structures generated from $\mathrm{HH}$ stage 5 including the hindbrain and spinal cord [57]. Indeed, our data do not contradict the role of prechordal mesoderm and of hedgehog signaling in brain induction (see also [52]. However, as argued above, the proposed induction by the notochord [57] does not fit to continuous and persistent shh expression 
along the whole floor plate area which emerges after the beginning of node regression and during early somitogenesis (this study). The same time window has been suggested to limit the period of floor plate induction in both mouse and chicken [63].

However, considering the dynamic mode of floor plate generation [9] the involvement of shh from the notochord in the induction of the newly emerged floor plate at later stages cannot be excluded. In our view, the mode of floor plate induction in regions posterior to the cervical spinal cord should be investigated in detail to clarify whether there are even more numerous mechanisms of floor plate induction.

\section{Universal or divergent mechanisms of initial neural patterning}

Further to the midline shh pattern in the chick embryo reported here and differing from data reported for mouse embryo $[10,18,43]$, our analysis of shh expression in rabbit and $X$. laevis embryos revealed an additional divergence of spatiotemporal expression patterns among vertebrates (cf. Table 1 and Additional file 4: Table 1). Axial mesoderm in the rabbit has initial strong shh expression followed by expression in the floor plate similar to the mouse. Two findings, however, have not been reported previously: we found that strong shh expression is especially confined to the lateral domain that overlaps with the nodal domain, thus indicating possible involvement of hedgehog signaling in initiation of paramedian nodal domains [69]. Furthermore, our analysis revealed an initially short shh domain in the posterior floor plate. The latter can be explained by contribution of the shh-positive node to both notochord and posterior floor plate. Importantly, patched has been shown to be expressed in the rabbit prospective floor plate already at stage 5 indicating activated hedgehog signaling, while HNF3-beta expression was not detectable [24, 25]. Interestingly, Indian hedgehog does not display typical midline patterning in rabbit although it is expressed in the node and weakly in the short adjacent region of the notochord where it may be involved in hedgehog signaling, while desert hedgehog is not expressed at rabbit perigastrulation stages [8]. In summary, early shh expression in the rabbit midline axial mesoderm, together with signs of activated hedgehog signaling in the prospective floor plate above, supports the classical model, assuming that shh expression in the floor plate is induced by shh signaling from the notochord.

In X. laevis, ectodermal shh expression also follows the mesodermal expression pattern, and the prospective floor plate is shh positive already at the end of the gastrula above both emerging notochord and the wide spread shhpositive anterior axial (prechordal) mesoderm. Therefore,
Table 1 Comparison of shh expression domains in equivalent axial structures of studied amniotes during notochord formation (HH/mammalian stage 5/6)

\begin{tabular}{|c|c|c|c|c|c|}
\hline & & \multirow[t]{2}{*}{ Organizer level } & \multicolumn{3}{|c|}{ Notochord level } \\
\hline & & & Posterior & Mid & Anterior \\
\hline \multirow[t]{2}{*}{ Rabbit } & Dorsal & + (node-epibl) & - (floorpl) & - (floorpl) & - (floorpl) \\
\hline & Ventral & + (node-mes) & $+($ not $)$ & $+($ not $)$ & $+($ not/pm) \\
\hline \multirow[t]{2}{*}{ Chick } & Dorsal & + (node-epibl) & + (floorpl) & + (floorpl) & - (floorpl) \\
\hline & Ventral & - (node-mes) & $-($ not $)$ & $+($ not $)$ & $+($ not/pm) \\
\hline
\end{tabular}

Labeling: not notochord, pm prechordal mesoderm, mes mesoderm, epibl epiblast, floorp/ floor plate

the induction of shh expression in the prospective floor plate of X. laevis is an early event and includes from its initiation the prospective brain region. Whether early shh expression in the floor plate is induced by dorsal mesoderm remains to be clarified although neither inhibition of hedgehog signaling with antisense morpholinos injected at the two-cell stage nor cyclopamine treatment from stage 8 was able to suppress substantially shh expression in the floor plate [54]. On the other hand, expression of patched 2 at mid-gastrula indicates active hedgehog signaling (Fig. 5h). Interestingly, shh is expressed in the anterior midline leading edge mesoderm tissue known to be involved in head and heart formation, as well as in the analogous domain in the chick embryo (Fig. 1b). Other genes of the hedgehog family are not expressed in the midline of $X$. laevis embryos [19].

\section{The role of the notochord}

Several experiments suggested that the notochord is a prerequisite for floor plate development $[37,59,90$, 91]. Node area excision in the gastrulating chick leads gives rise-apart from completely normally developed embryos [32, 61] -also to notochordless embryos, which display a.o. abnormal formation of neural folds, neural tube closure as well as the absence of typical floor plate cells [74]. At the same time, excision of the notochord piece in the chick anterior to the node at early stage 5 [50] does not affect shh expression in the midbrain and hindbrain. Although the excision of the node at 5-6 somite stage leads to midline abnormalities, regions with normal floor plate developed in notochordless areas [11]. Furthermore, the excision of the notochord at stage 9-10 leads to abnormal morphological development of floor plate in some areas of the neural tube, whereas other areas without the notochord do not display neural tube abnormalities; thus, it may be assumed that morphologically correct floor plate can develop without the underlying notochord [90]. An old study may help to interpret these observations: in the Triturus embryo 
with an absent notochord, the resulting abnormal floor plate was always associated with the fusion of somite material under the neural tube and, if somites were not fused, the neural tube developed a normal morphology [38]. A similar constellation may be true for the notochordless chick embryo [90] where the abnormal neural tube is seen above fused somites, whereas in other areas the neural tube resembles a normal shape.

\section{Organizer topography and the patterning of the neural tube}

On the basis of the results presented here, we hypothesize that divergent induction of shh expression in the midline neuroectoderm is due to divergent topography and morphogenetic movements during gastrulation. Evolution of vertebrate gastrulation has been proposed to be driven by increasing of yolk mass [5], which may lead via premature posterior activation of PCP pathway to stepwise transformation of circular blastopore into straight primitive streak of amniotes [7, 78, 80, 93]. This modified topography of organizer in turn may affect mechanisms of notochord formation. In the chick (Fig. 7), the notochord is laid down during so-called node (or primitive streak) regression [77], a process that is accompanied by a shift of the relative node position to the posterior pole of the embryo. Just prior to regression, the node tissue undergoes counterclockwise rotation [15, 27]. This rotation breaks the symmetry of the horseshoelike shh domain located anterior to the node and transforms it into left-sided [15, 27, 39]. We propose that the notochord progenitor domain, which is located in the middle of the node [70] and at this stage does not express shh [86], is shifted to the right side (see Fig. 7). During primitive streak regression, tissues lateral to the node are shifted posteriorly, whereas the prospective neural plate undergoes elongation [68]. Therefore, the ectodermal shh domain also undergoes elongation which creates a stripelike shh expression domain in the future floor plate (cf. Additional file 3: Fig. 3) which persists during studied stages and makes the inductive influence from the notochord unnecessary.

In the mouse and in the rabbit, however (Fig. 8), notochord formation is not accompanied by noticeable node regression $[33,96]$. The major part of the murine notochord seems to be formed by convergent extension of the cells deriving from $s h$-positive node tissue. Whether the posterior part of the floor plate is also derived from the node is still a matter of debate. During notochord formation, the node remains symmetrical and bears symmetrical shh domain [25]. The axial mesoderm is shh positive along its whole length. The neural plate extension occurs by growth of tissue distant to the organizer [92]. Therefore, the induction of the floor plate requires external inductive stimuli, which are enabled by growth of the notochord beneath the prospective floor plate tissue (cf. Figure 8).

In X. laevis, finally (Fig. 9), where the inductive interactions occur at an earlier stage, the notochord is generated by intercalation of dorsal mesoderm, which prior to invagination lies adjacent to the prospective neural tissue (Fig. 9). We are therefore tempted to speculate that the initial floor plate induction may occur at the stage where

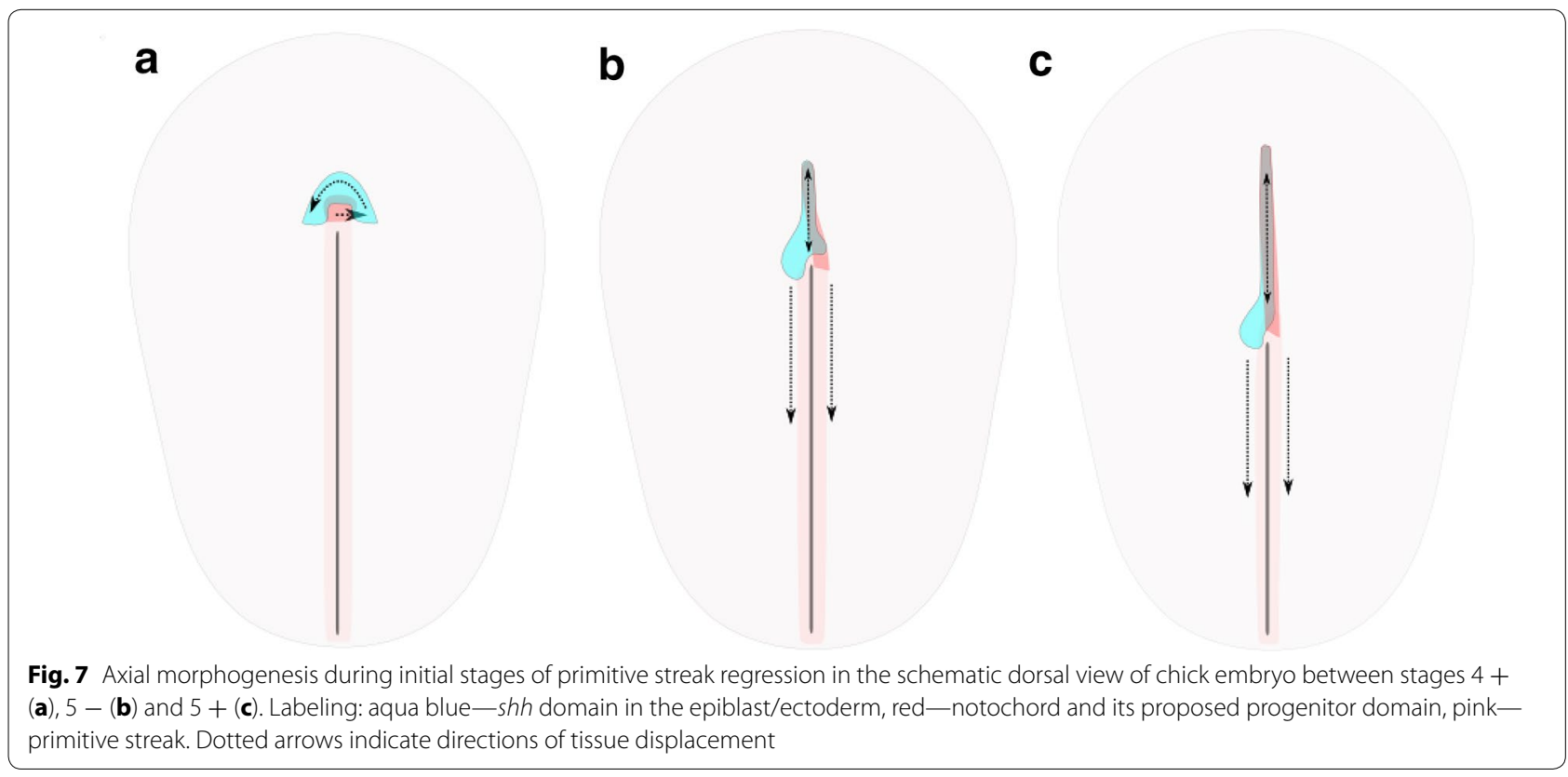




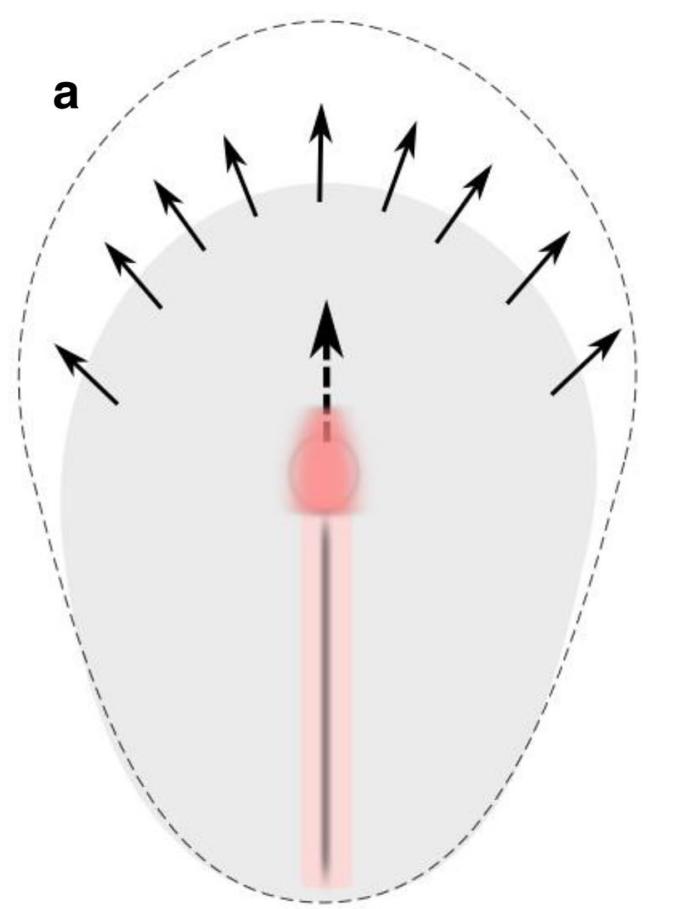

b

Fig. 8 Expansion of prospective neural plate and growth of notochord from the node in the schematic dorsal view of rabbit embryo. a prior to the notochord formation (stage 4), b early notochord stage (stage 5). Labeling: arrows-growth of the blastoderm, dotted arrow-direction of notochord growth, red —notochord, pink — primitive streak, black — primitive groove

the neural tissue and mesoderm are arranged in close spatial planar neighborhood.

\section{Hedgehog expression and evolution of floor plate induction in chordates}

In zebrafish, shh expression is initiated at $60 \%$ epiboly in the dorsal mesoderm, whereas already at $100 \%$ epiboly, shh is expressed in the midline anterior neuroectoderm above negative mesoderm, suggesting early induction
[34]. Interestingly, neuroectodermal expression is initiated in the forebrain and progressively extends to the posterior pole, whereas in the chicken embryo expression extends in the opposite direction, hence indicating an additional divergence in the initiation of shh expression pattern. As already mentioned, the presence of the notochord is not required for zebrafish floor plate development, also suggesting that induction of shh in the zebrafish floor plate may be independent from the
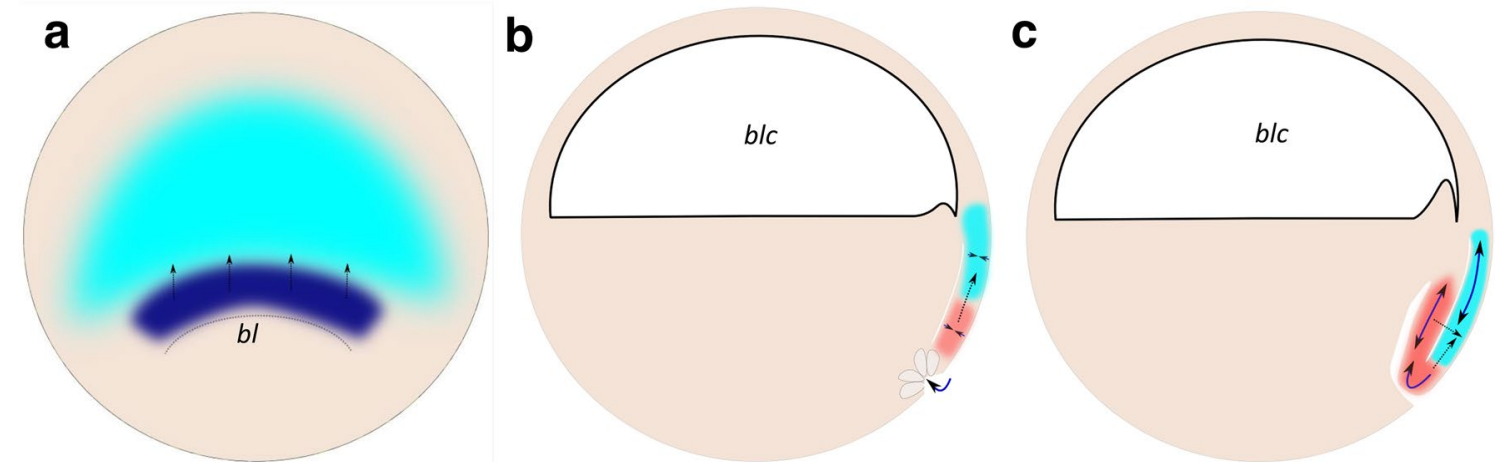

Fig. 9 Schematic view of Xenopus laevis embryo during early and mid-gastrula: a dorsal view, b and $\mathbf{c}$ midline sagittal view. Labeling: red axial mesoderm, aqua blue —-midline neuroectoderm, dark blue_shh expression domain, gray_-bottle cells; blc_-blastocoel, bl_-blastopore, dotted arrows - direction of proposed induction, blue arrows — directions of morphogenetic movements, dotted curve in a-dorsal blastopore lip 
signal from the notochord and may occur at early stage. Importantly, other genes of hedgehog family are also expressed in the zebrafish midline structures. Moreover, this midline expression shows a segregated pattern: the expression of an orthologue of desert hedgehog is initiated at $50 \%$ epiboly in the embryonic shield and is at $90 \%$ epiboly expressed in the entire presumptive floor plate [21], whereas the expression of the Indian hedgehog orthologue is confined exclusively to the notochord [16]. Remarkably, expression of hedgehog family members at early stages of vertebrate development is highly divergent. In addition to axial expression of shh, a weak expression of Indian hedgehog was detected in the node and adjacent notochord of some mammals [8, 97], whereas in Xenopus [19] and chicken embryos (this report), the midline structures expressed sonic hedgehog only. These data are reminiscent of recurrent switching the function of paralogues shown for Snail1 and Snail2 in amniotes [41] and indicates functional divergence of hedgehog paralogues.

It has been suggested that the hedgehog family arose from single hedgehog gene also found in basal chordate amphioxus [72], whereas the Ciona intestinalis possesses two members (Ci-hh1 and Ci-hh2) that emerged in independent duplication events [84]. Analysis of hedgehog expression in Ciona shows expression of $\mathrm{Ci}-\mathrm{hh} 2$ in the ventral cells of the neural tube tissue prior to its expression in the notochord [84]. Initial shh expression in the ventral neural tube may be related to invariant development of cell lineage and early axis determination in ascidian embryogenesis, which functionally have lost organizer tissue although some inductive interaction and even regulative capacities have been observed [6, 47, 82, 83]. However, in amphioxus with its highly regulative development $[87,88]$ this dynamics may display an inverse spatiotemporal relation: although only wholemount views from early stages were shown, the authors suggest that initially the hedgehog expression is localized in the presumptive endoderm and the notochord [72]. The situation in amphioxus may represent ancestral mode of floor plate induction.

Comparison of reported data about initiation of axial hedgehog expression in chordates indicates evolutionary divergence in organizer tissues capable of floor plate induction and even patterning (Fig. 10). Phenotypic evolution has been proposed to be driven by developmental plasticity $[56,95]$ characterized by self-adjustment of developmental processes producing new phenotypic outcomes (cf. [55]. The role of such processes in the evolution of amniote gastrulation is supported by observation of experimentally induced modified gastrulation forms in rabbit and chicken embryo $[1,78,93]$. Altered gastrulation movements may facilitate changes in topography of axial organs and lead to the shift of expression domains, therefore driving the evolution of floor plate induction. In the next step, genetic accommodation and assimilation may be involved to ensure the stabilization of expression domains based on reciprocal molecular interactions [35, $45,95]$.

Finally, developmental plasticity of floor plate inducing mechanisms is supported by recent findings of autonomous differentiation and floor plate marker induction in ES derived tissue: treatment of dorsalized neural tube organoids with retinoic acid leads to spontaneous symmetry breaking and dorsoventral patterning showing plasticity of dorsoventral patterning which may be induced by different triggers [30].

\section{Conclusions}

Our comparative analysis of the spatiotemporal dynamics of shh expression indicates different sequences of shh induction in the prospective floor plate in several key vertebrate species and an evolutionary divergence of floor plate induction among vertebrates (Table 1 and Additional file 4: Table 1). Furthermore, it challenges (at least in the case of the chicken embryo) the model where the notochord is the primary source of hedgehog signaling in the floor plate (cf. Additional file 3: Fig. 3) by providing new observations and testable conclusions: shh expression in the chick prospective floor plate is initiated prior to mesoderm migration, there is no indication for downregulation of shh in the floor plate during early somitogenesis, and freshly laid down chick notochord is shh negative between $\mathrm{HH}$ stages 5 - and 8. Therefore, our data support and extend, by applying them to earlier stages, a similar proposal originally formulated by Le Douarine and co-workers [36, 85]. We further suggest that the mode of floor plate induction is related to the mechanism of notochord formation and propose that the initial induction of the floor plate marker shh in the future ventral cells of the neural tube evolves to adapt to the changing topography of interacting tissues which are the result of divergent morphogenetic movements in different embryo shapes prior and during gastrulation. Especially the "premature" expression of shh in the chick prospective floor plate seems to point to a spatiotemporal interdependence of axial organ formation, node regression, and left-right symmetry breaking, and to an involvement of early planar interaction within the epiblast. Further comparative 


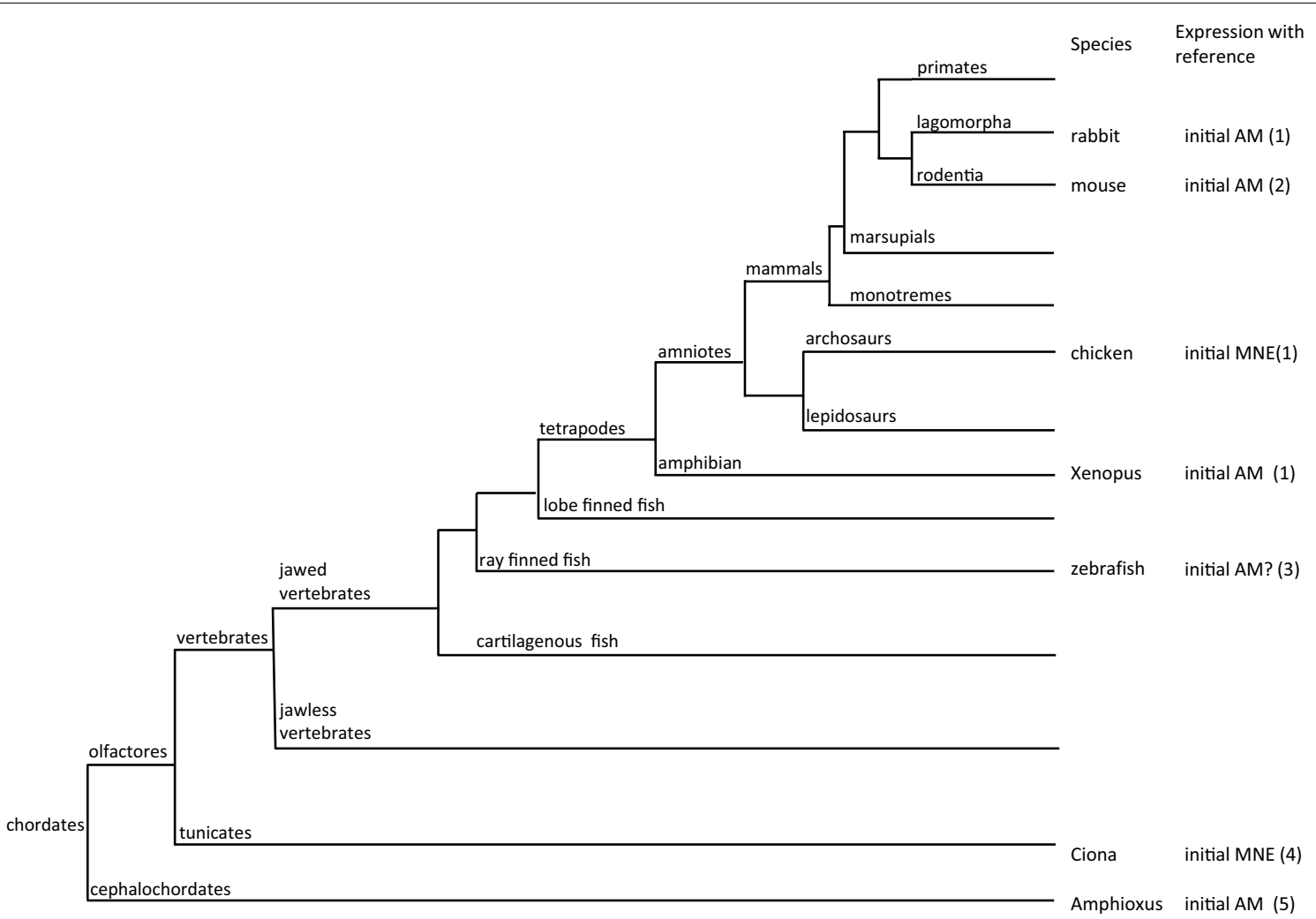

Fig. 10 Initial shh expression in context of phylogeny of chordate. MNE midline neuroectoderm, AM axial mesoderm. References: 1—this report, 2-[10], 3-[34], 4-[84], 5-[72]

and functional studies may now be designed to test this hypothesis.

\section{Additional files}

Additional file 1: Fig. 1. Expression of shh at the beginning of notochord formation. A: whole-mount view, B-D: transversal technovit sections at the levels shown in A.

Additional file 2: Fig. 2. A. Expression of shh at stage $4+$, note absent reaction in the pit. B-D of patched 2 expression at stages $4-(B), 4(C)$ and $4+(D)$; note expression domain anterior to the node corresponding to the midline neuroectoderm. Arrow-the node area.

Additional file 3: Fig. 3. Schematic transversal view of a chicken embryo at the level of the posterior notochord. A: ventral to dorsal floor plate induction in the classical view-shh is first expressed in the notochord and induces shh in floor plate. Shh protein from both sources forms a gradient. B: modified model demonstrating early shh expression and shh gradient formation in the floor plate. Labeling: pink-notochord, bluefloor plate, green—hypoblast/endoderm, brown — paraxial mesoderm, arrows - gradient formation and induction.

Additional file 4: Table 1. Summary of shh expression in equivalent axial structures in chicken, rabbit and Xenopus laevis.

\section{Authors' contributions}

SK, NT, KH and CV collected and prepared specimens, and performed in situ hybridization analysis, NT developed the concept, and NT and SK performed data analysis and wrote the first version of the manuscript. All authors contributed to the final version of the manuscript. All authors read and approved the final manuscript.

\section{Author details}

${ }^{1}$ Department of Embryology, Faculty of Biology, Lomonosov State University Moscow, Leninskie Gory, 1, Builung 12, Moscow, Russia 119234. ${ }^{2}$ Koltzov Institute of Developmental Biology, Russian Academy of Sciences, Vavilova Str. 26, Moscow, Russia 119991. ${ }^{3}$ Center for Nanoscale Microscopy and Molecular Physiology of the Brain (CNMPB), Institute of Developmental Biochemistry, University Medical Center Göttingen, Justus-von-Liebig-Weg 11, 37077 Göttingen, Germany. ${ }^{4}$ Institute of Anatomy and Embryology, University Medical Center Göttingen, Kreuzbergring 36, 37085 Göttingen, Germany.

\section{Acknowledgements}

The authors acknowledge Cliff Tabin and Anja Fischer for cDNA probes and Kirsten Falk-Stietenroth, Heike Faust, Irmgard Weiss, Hans-Georg Sydow and Katja Ditter for excellent technical work.

\section{Competing interests}

The authors declare that they have no competing interests.

\section{Availability of data and supporting materials}

All plasmids and raw data are available upon request following publication.

\section{Consent for publication}

All authors have approved the manuscript for submission.

\section{Ethics approval and consent to participate}

All protocols applied to animal husbandry and animal handling in this study are in agreement with the German Animal Welfare Act (Tierschutzgesetz) and are supervised by LAVES (Niedersächsisches Landesamt für Verbraucherschutz, Oldenburg, Germany). The reference number at LAVES is T10/20. 


\section{Funding}

The work of SK is supported by federal project 0108-2018-0003, and the work of KH is supported by DFG Center for Nanoscale Microscopy and Molecular Physiology of the Brain.

\section{Publishers' Note}

Springer Nature remains neutral with regard to jurisdictional claims in published.

Received: 17 August 2017 Accepted: 18 December 2017

Published online: 31 January 2018

\section{References}

1. Alev C, Wu Y, Nakaya Y, Sheng G. Decoupling of amniote gastrulation and streak formation reveals a morphogenetic unity in vertebrate mesoderm induction. Development. 2013;140:2691-6.

2. Altaba ARI, Jessel TM, Roelink H. Restrictions to floor plate induction by hedgehog and winged-helix genes in the neural-tube of frog embryos. Mol Cell Neurosci. 1995;6:106-21.

3. Anderson C, Stern CD. Organizers in development. Curr Top Dev Biol. 2016;117:435-54

4. Ang SL, Rossant J. HNF-3 beta is essential for node and notochord formation in mouse development. Cell. 1994;78:561-74.

5. Arendt D, Nubler-Jung K. Rearranging gastrulation in the name of yolk: evolution of gastrulation in yolk-rich amniote eggs. Mech Dev. 1999:81:3-22

6. Bates WR. Development of myoplasm-enriched ascidian embryos. Dev Biol. 1988;129:241-52.

7. Bertocchini F, Alev C, Nakaya Y, Sheng G. A little winning streak: the reptilian-eye view of gastrulation in birds. Dev Growth Differ, 2013:55:52-9.

8. Bitzer E. Establishment of a new in vitro Culture System and functional Analysis of Sonic Hedgehog and FGF8 in the Determination of Laterality in the Rabbit Embryo. Ph.D. thesis, Institut für Zoologie. Hohenheim: University of Hohenheim; 2009, p. 119.

9. Catala M, Teillet MA, De Robertis EM, Le Douarin ML. A spinal cord fate map in the avian embryo: while regressing, Hensen's node lays down the notochord and floor plate thus joining the spinal cord lateral walls. Development. 1996;122:2599-610.

10. Chamberlain CE, Jeong J, Guo C, Allen BL, McMahon AP. Notochordderived Shh concentrates in close association with the apically positioned basal body in neural target cells and forms a dynamic gradient during neural patterning. Development. 2008;135:1097-106.

11. Charrier JB, Teillet MA, Lapointe F, Le Douarin NM. Defining subregions of Hensen's node essential for caudalward movement, midline development and cell survival. Development. 1999:126:4771-83.

12. Chizhikov WV, Millen KJ. Roof plate-dependent patterning of the vertebrate dorsal central nervous system. Dev Biol. 2005;277:287-95.

13. Cohen M, Briscoe J, Blassberg R. Morphogen interpretation: the transcriptional logic of neural tube patterning. Curr Opin Genet Dev. 2013:23:423-8.

14. Cruz C, Ribes V, Kutejova E, Cayuso J, Lawson V, Norris D, Stevens J, Davey M, Blight K, Bangs F, Mynett A, Hirst E, Chung R, Balaskas N, Brody SL, Marti E, Briscoe J. Foxj1 regulates floor plate cilia architecture and modifies the response of cells to sonic hedgehog signalling. Development. 2010;137:4271-82.

15. Cui $C$, Little CD, Rongish BJ. Rotation of organizer tissue contributes to left-right asymmetry. Anat Rec (Hoboken). 2009;292:557-61.

16. Currie PD, Ingham PW. Induction of a specific muscle cell type by a hedgehog-like protein in zebrafish. Nature. 1996;382:452-5.

17. Dathe V, Gamel A, Manner J, Brand-Saberi B, Christ B. Morphological left-right asymmetry of Hensen's node precedes the asymmetric expression of Shh and Fgf8 in the chick embryo. Anat Embryol (Berl). 2002;205:343-54

18. Echelard Y, Epstein DJ, St-Jacques B, Shen L, Mohler J, McMahon JA, McMahon AP. Sonic hedgehog, a member of a family of putative signaling molecules, is implicated in the regulation of CNS polarity. Cell. 1993:75:1417-30.

19. Ekker SC, McGrew LL, Lai CJ, Lee JJ, von Kessler DP, Moon RT, Beachy PA. Distinct expression and shared activities of members of the hedgehog gene family of Xenopus laevis. Development. 1995;121:2337-47.

20. Ekker SC, Ungar AR, Greenstein P, von Kessler DP, Porter JA, Moon RT, Beachy PA. Patterning activities of vertebrate hedgehog proteins in the developing eye and brain. Curr Biol. 1995;5:944-55.

21. Etheridge LA, Wu T, Liang JO, Ekker SC, Halpern ME. Floor plate develops upon depletion of tiggy-winkle and sonic hedgehog. Genesis. 2001;30:164-9.

22. Fernandez-Garre P, Rodriguez-Gallardo L, Alvarez IS, Puelles L. A neural plate fate map at stage $\mathrm{HH} 4$ in the chick: methodology and preliminary data. Brain Res Bull. 2002;57:293-5.

23. Fernandez-Garre P, Rodriguez-Gallardo L, Gallego-Diaz V, Alvarez IS, Puelles L. Fate map of the chicken neural plate at stage 4. Development. 2002;129:2807-22.

24. Fischer A. Links-Rechts-Achsenentwicklung im Kaninchenembryo, Fakultät für Bio- und Geowissenschaften. Karlsruhe: Universität Karlsruhe, Forschungszentrum Karlsruhe $\mathrm{GmbH} ; 2002$

25. Fischer A, Viebahn C, Blum M. FGF8 acts as a right determinant during establishment of the left-right axis in the rabbit. Curr Biol. 2002:12:1807-16.

26. Goulding M, Lanuza G, Sapir T, Narayan S. The formation of sensorimotor circuits. Curr Opin Neurobiol. 2002;12:508-15.

27. Gros J, Feistel K, Viebahn C, Blum M, Tabin CJ. Cell movements at Hensen's node establish left/right asymmetric gene expression in the chick. Science. 2009;324:941-4

28. Halpern ME, Ho RK, Walker C, Kimmel CB. Induction of muscle pioneers and floor plate is distinguished by the zebrafish no tail mutation. Cell. 1993;75:99-111.

29. Hamburger $V$, Hamilton HL. A series of normal stages in the development of the chick embryo. J Morphol. 1951:88:49-92.

30. Ishihara K, Ranga A, Lutolf MP, Tanaka EM, Meinhardt A. Reconstitution of a patterned neural tube from single mouse embryonic stem cells. Methods Mol Biol. 2017:1597:43-55.

31. Johnson RL, Riddle RD, Laufer E, Tabin C. Sonic hedgehog: a key mediator of anterior-posterior patterning of the limb and dorso-ventral patterning of axial embryonic structures. Biochem Soc Trans. 1994;22:569-74.

32. Joubin K, Stern CD. Molecular interactions continuously define the organizer during the cell movements of gastrulation. Cell. 1999;98:559-71.

33. Kinder SJ, Tsang TE, Wakamiya M, Sasaki H, Behringer RR, Nagy A, Tam PP. The organizer of the mouse gastrula is composed of a dynamic population of progenitor cells for the axial mesoderm. Development. 2001;128:3623-34.

34. Krauss S, Concordet JP, Ingham PW. A functionally conserved homolog of the Drosophila segment polarity gene hh is expressed in tissues with polarizing activity in zebrafish embryos. Cell. 1993;75:1431-44.

35. Laland KN, Uller T, Feldman MW, Sterelny K, Muller GB, Moczek A, Jablonka E, Odling-Smee J. The extended evolutionary synthesis: its structure, assumptions and predictions. Proc Biol Sci R Soc. 2015:282:20151019.

36. Le Douarin NM, Halpern ME. Discussion point. Origin and specification of the neural tube floor plate: insights from the chick and zebrafish. Curr Opin Neurobiol. 2000;10:23-30.

37. Lehmann FE. Die Bedeutung der Unterlagerung für die Entwicklung der Medullarplatte von Triton. W. Roux' Archiv f. Entwicklungsmechanik. 1928:113:123-71.

38. Lehmann FE. Die Entwicklung von Rückenmark, Spinalganglien und Wirbelanlagen in chordalosen Körperregionen von Tritonlarven. Rev Suisse Zool. 1935:42:402-15.

39. Levin M, Johnson RL, Stern CD, Kuehn M, Tabin C. A molecular pathway determining left-right asymmetry in chick embryogenesis. Cell. 1995;82:803-14.

40. Liem KF Jr, Tremml G, Roelink H, Jessell TM. Dorsal differentiation of neural plate cells induced by BMP-mediated signals from epidermal ectoderm. Cell. 1995:82:969-79.

41. Locascio A, Manzanares M, Blanco MJ, Nieto MA. Modularity and reshuffling of Snail and Slug expression during vertebrate evolution. Proc Natl Acad Sci USA. 2002:99:16841-6.

42. Lopez-Sanchez C, Garcia-Martinez V, Schoenwolf GC. Localization of cells of the prospective neural plate, heart and somites within the primitive 
streak and epiblast of avian embryos at intermediate primitive-streak stages. Cells Tissues Organs. 2001;169:334-46.

43. Marti E, Takada R, Bumcrot DA, Sasaki H, McMahon AP. Distribution of Sonic hedgehog peptides in the developing chick and mouse embryo. Development. 1995;121:2537-47.

44. Megason SG, McMahon AP. A mitogen gradient of dorsal midline Wnts organizes growth in the CNS. Development. 2002;129:2087-98.

45. Moczek AP. The nature of nurture and the future of evodevo: toward a theory of developmental evolution. Integr Comp Biol. 2012;52:108-19.

46. Nieuwkoop PD, Faber J. Normal table of Xenopus laevis (Daudin). A systematical and chronological survey of the development from the fertilized egg till the end of metamorphosis. 2nd ed. Amsterdam: NorthHolland Pub. Co.; 1967.

47. Nishida H. Developmental potential for tissue differentiation of fully dissociated cells of the ascidian embryo. Roux Arch Dev Biol. 1992;201:81-7.

48. Odenthal J, van Eeden FJ, Haffter P, Ingham PW, Nusslein-Volhard C. Two distinct cell populations in the floor plate of the zebrafish are induced by different pathways. Dev Biol. 2000;219:350-63.

49. Otto A, Pieper T, Viebahn C, Tsikolia N. Early left-right asymmetries during axial morphogenesis in the chick embryo. Genesis. 2014:52:614-25.

50. Patten I, Kulesa P, Shen MM, Fraser S, Placzek M. Distinct modes of floor plate induction in the chick embryo. Development. 2003:130:4809-21.

51. Pearse RV 2nd, Vogan KJ, Tabin CJ. Ptc1 and Ptc2 transcripts provide distinct readouts of Hedgehog signaling activity during chick embryogenesis. Dev Biol. 2001;239:15-29.

52. Pera EM, Kessel M. Patterning of the chick forebrain anlage by the prechordal plate. Development. 1997;124:4153-62.

53. Peterson KA, Nishi Y, Ma W, Vedenko A, Shokri L, Zhang X, McFarlane M, Baizabal JM, Junker JP, van Oudenaarden A, Mikkelsen T, Bernstein BE, Bailey TL, Bulyk ML, Wong WH, McMahon AP. Neural-specific Sox2 input and differential Gli-binding affinity provide context and positional information in Shh-directed neural patterning. Genes Dev. 2012;26:2802-16.

54. Peyrot SM, Wallingford JB, Harland RM. A revised model of Xenopus dorsal midline development: differential and separable requirements for Notch and Shh signaling. Dev Biol. 2011;352:254-66.

55. Pigliucci M, Müller G, Konrad Lorenz Institute for Evolution and Cognition Research. Evolution, the extended synthesis. Cambridge: MIT Press; 2010.

56. Pigliucci M, Murren CJ, Schlichting CD. Phenotypic plasticity and evolution by genetic assimilation. J Exp Biol. 2006;209:2362-7.

57. Placzek M, Briscoe J. The floor plate: multiple cells, multiple signals. Nat Rev Neurosci. 2005;6:230-40.

58. Placzek M, Dodd J, Jessell TM. Discussion point. The case for floor plate induction by the notochord. Curr Opin Neurobiol. 2000;10:15-22.

59. Placzek M, Tessier-Lavigne M, Yamada T, Jessell T, Dodd J. Mesodermal control of neural cell identity: floor plate induction by the notochord. Science. 1990;250:985-8.

60. Pourquie O, Coltey M, Teillet MA, Ordahl C, Le Douarin NM. Control of dorsoventral patterning of somitic derivatives by notochord and floor plate. Proc Natl Acad Sci USA. 1993;90:5242-6.

61. Psychoyos D, Stern CD. Restoration of the organizer after radical ablation of Hensen's node and the anterior primitive streak in the chick embryo. Development. 1996;122:3263-73.

62. Puelles L, Fernandez-Garre P, Sanchez-Arrones L, Garcia-Calero E, Rodriguez-Gallardo L. Correlation of a chicken stage 4 neural plate fate map with early gene expression patterns. Brain Res Rev. 2005:49:167-78.

63. Ribes V, Balaskas N, Sasai N, Cruz C, Dessaud E, Cayuso J, Tozer S, Yang LL, Novitch B, Marti E, Briscoe J. Distinct Sonic Hedgehog signaling dynamics specify floor plate and ventral neuronal progenitors in the vertebrate neural tube. Genes Dev. 2010;24:1186-200

64. Ribes V, Briscoe J. Establishing and interpreting graded Sonic Hedgehog signaling during vertebrate neural tube patterning: the role of negative feedback. Cold Spring Harb Perspect Biol. 2009;1:a002014.

65. Roelink H, Augsburger A, Heemskerk J, Korzh V, Norlin S, Ruiz i Altaba A, Tanabe Y, Placzek M, Edlund T, Jessell TM, et al. Floor plate and motor neuron induction by vhh-1, a vertebrate homolog of hedgehog expressed by the notochord. Cell. 1994:76:761-75.

66. Ruiz i Altaba A, Placzek M, Baldassare M, Dodd J, Jessell TM. Early stages of notochord and floor plate development in the chick embryo defined by normal and induced expression of HNF-3 beta. Dev Biol. 1995;170:299-313.
67. Schauerte HE, van Eeden FJ, Fricke C, Odenthal J, Strahle U, Haffter P. Sonic hedgehog is not required for the induction of medial floor plate cells in the zebrafish. Development. 1998;125:2983-93.

68. Schoenwolf GC. Cell movements driving neurulation in avian embryos. Dev Suppl. 1991;2:157-68.

69. Schroder SS, Tsikolia N, Weizbauer A, Hue I, Viebahn C. Paraxial nodal expression reveals a novel conserved structure of the left-right organizer in four mammalian species. Cells Tissues Organs. 2016;201:77-87.

70. Selleck MA, Stern CD. Fate mapping and cell lineage analysis of Hensen's node in the chick embryo. Development. 1991;112:615-26.

71. Shih J, Fraser SE. Characterizing the zebrafish organizer: microsurgical analysis at the early-shield stage. Development. 1996;122:1313-22.

72. Shimeld SM. The evolution of the hedgehog gene family in chordates: insights from amphioxus hedgehog. Dev Genes Evol. 1999;209:40-7.

73. Sive HL, Grainger RM, Harland RM. Early development of Xenopus laevis: a laboratory manual. Cold Spring Harbor: Cold Spring Harbor Laboratory Press; 2000.

74. Smith JL, Schoenwolf GC. Notochordal induction of cell wedging in the chick neural plate and its role in neural tube formation. J Exp Zool. 1989;250:49-62.

75. Spemann H. Experimentelle Beiträge zu einer Theorie der Entwicklung. Berlin: Springer; 1936

76. Spemann $\mathrm{H}$, Mangold $\mathrm{H}$. Induction of embryonic primordia by implantation of organizers from a different species (Reprinted from Archiv Mikroskopische Anatomie Entwicklungsmechanik, vol 100, p. 599-638, 1924). Int J Dev Biol. 2001;45:13-38.

77. Spratt NT Jr. Regression and shortening of the primitive streak in the explanted chick blastoderm. J Exp Zool. 1947;104:69-100.

78. Stankova V, Tsikolia N, Viebahn C. Rho kinase activity controls directional cell movements during primitive streak formation in the rabbit embryo. Development. 2015;142:92-8.

79. Stern CD. Gastrulation in the chick. In: Stern CD, editor. Gastrulation, from cells to embryo. New York: Cold Spring Harbor; 2004.

80. Stower MJ, Bertocchini F. The evolution of amniote gastrulation: the blastopore-primitive streak transition. Dev Biol: Wiley interdisciplinary reviews; 2017. p. 6.

81. Streit A, Berliner AJ, Papanayotou C, Sirulnik A, Stern CD. Initiation of neural induction by FGF signalling before gastrulation. Nature. 2000;406:74-8.

82. Swalla BJ. Mechanisms of gastrulation and tail formation in ascidians. Microsc Res Tech. 1993;26:274-84.

83. Swalla BJ, Jeffery WR. Interspecific hybridization between an anural and urodele ascidian: differential expression of urodele features suggests multiple mechanisms control anural development. Dev Biol. 1990;142:319-34.

84. Takatori N, Satou Y, Satoh N. Expression of hedgehog genes in Ciona intestinalis embryos. Mech Dev. 2002;116:235-8.

85. Teillet MA, Lapointe F, Le Douarin NM. The relationships between notochord and floor plate in vertebrate development revisited. Proc Natl Acad Sci USA. 1998:95:11733-8.

86. Tsikolia N, Schroder S, Schwartz P, Viebahn C. Paraxial left-sided nodal expression and the start of left-right patterning in the early chick embryo. Differ Res Biol Divers. 2012;84:380-91.

87. Tung TC, Wu SC, Tung YY. The developmental potencies of the blastomere layers in Amphioxus egg at the 32-cell stage. Sci Sin. 1960;9:119-41.

88. Tung TC, Wu SC, Tung YY. Differentiation of the prospective ectodermal and entodermal cells after transplantation to new surroundings in Amphioxus. Sci Sin. 1965;14:1785-94.

89. Uygur A, Young J, Huycke TR, Koska M, Briscoe J, Tabin CJ. Scaling pattern to variations in size during development of the vertebrate neural tube. Dev Cell. 2016:37:127-35.

90. van Straaten HW, Hekking JW. Development of floor plate, neurons and axonal outgrowth pattern in the early spinal cord of the notochorddeficient chick embryo. Anat Embryol (Berl). 1991;184:55-63.

91. van Straaten HW, Hekking JW, Wiertz-Hoessels EJ, Thors F, Drukker J. Effect of the notochord on the differentiation of a floor plate area in the neural tube of the chick embryo. Anat Embryol (Berl). 1988;177:317-24.

92. Viebahn C. Gastrulation in the rabbit. In: Stern CD, editor. Gastrulation, from cells to embryo. New York: Cold Spring Harbor; 2004. p. 263-74.

93. Voiculescu O, Bertocchini F, Wolpert L, Keller RE, Stern CD. The amniote primitive streak is defined by epithelial cell intercalation before gastrulation. Nature. 2007:449:1049-52. 
94. Voiculescu O, Bodenstein L, Lau IJ, Stern CD. Local cell interactions and self-amplifying individual cell ingression drive amniote gastrulation. ELife. 2014;3:e01817.

95. West-Eberhard MJ. Developmental plasticity and the origin of species differences. Proc Natl Acad Sci USA. 2005;102(Suppl 1):6543-9.

96. Yamanaka Y, Tamplin OJ, Beckers A, Gossler A, Rossant J. Live imaging and genetic analysis of mouse notochord formation reveals regional morphogenetic mechanisms. Dev Cell. 2007;13:884-96.
97. Zhang XM, Ramalho-Santos M, McMahon AP. Smoothened mutants reveal redundant roles for Shh and Ihh signaling including regulation of L/R symmetry by the mouse node. Cell. 2001;106:781-92.

\section{Submit your next manuscript to BioMed Central and we will help you at every step:}

- We accept pre-submission inquiries

- Our selector tool helps you to find the most relevant journal

- We provide round the clock customer support

- Convenient online submission

- Thorough peer review

- Inclusion in PubMed and all major indexing services

- Maximum visibility for your research

Submit your manuscript at

www.biomedcentral com/submit 